\title{
OBITUARY
}

\section{A tribute to Dr Peter MacLeod}

\section{Shawn Aaron MD MSc FRCPC}

I is with deep sadness that I announce the passing of Dr Peter Macleod on Friday, November 6, 2009, at 69 years of age after a courageous battle with cancer. Peter was born in Montreal (Quebec) and grew up in Halifax (Nova Scotia), Winnipeg (Manitoba) and Saskatoon (Saskatchewan), before returning to Montreal to study medicine at McGill University. His postgraduate training was completed at McGill and Queen's (Kingston, Ontario) Universities, and Albert Einstein Medical School in New York City. After seven years of practice in Montreal, he went to Ottawa in 1977 to work as a respirologist at the Ottawa Hospital and University of Ottawa (Ottawa, Ontario). He was the recipient of many accolades and awards, and was highly respected and loved as a physician, teacher, mentor and friend. Peter served as President of the Canadian Thoracic Society (1989 to 1990), Chair of The Canadian Lung Association Board of Directors (1993 to 1994) and, most recently, as Chief Medical Spokesperson for The Lung Association. The Canadian Thoracic Society and The Lung Association extends their deepest sympathies to Dr Macleod's wife Margaret, their children, extended family and friends.

Dr Peter MacLeod worked as a respiratory physician and as a professor in the Department of Medicine at the Ottawa Hospital for more than 30 years. He was a gracious, kind, soft-spoken man. One of the remarkable things about Peter is that he would never raise his voice, get angry or become flustered. The hospital environment can be extremely chaotic, but Peter, through his gentle calmness, could restore order to difficult situations simply by being present. A sense of cool, unflappable competence radiated from him, and his gentle presence and soft words could soothe patients, hospital staff and residents alike.

Peter will be remembered by his colleagues as the consummate physician. He was an expert clinician, who possessed a wealth of more than 40 years of clinical experience. His colleagues would invariably come to him with their most difficult cases for advice on diagnosis and treatment. His friendly demeanor, graceful tolerance and respect for other people meant that Peter was always one of the most beloved members of our division.

Peter will also be remembered as an expert teacher and mentor. An afternoon in his clinic was often a life-changing experience for young medical students. Unlike most of us, Peter would deliberately book fewer patients into his clinics if he knew he would be teaching a young student or resident. His devotion to teaching and educating the next generation of doctors was extraordinary. I would occasionally interview these medical students or residents after they exited Peter's clinic and they would be incredibly excited, energized, and grateful to Peter for showing them the beauty and grace that lies behind the practice of compassionate medicine.

Our city and our hospital were made much richer when Peter chose to work here 32 years ago. We will miss him dearly.

University of Ottawa, Ottawa, Ontario

Correspondence: Dr Shawn Aaron, Division of Respiratory Medicine, The Ottawa Hospital, 501 Smyth Road, Ottawa Ontario K1H 8L6.

Telephone 613-737-8899, e-mail saaron@ottawahospital.on.ca 


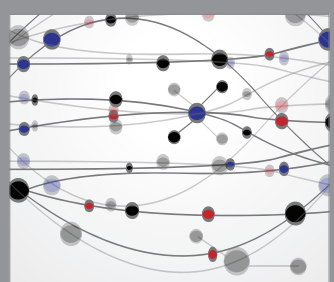

The Scientific World Journal
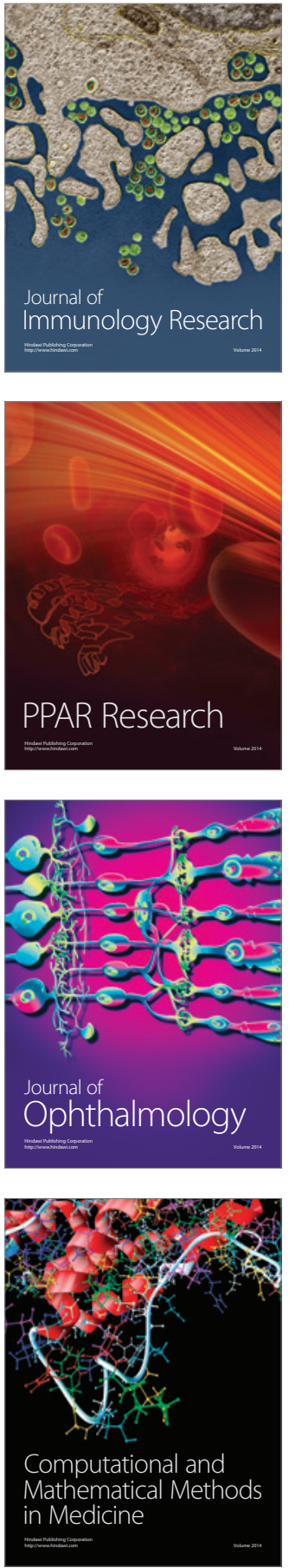

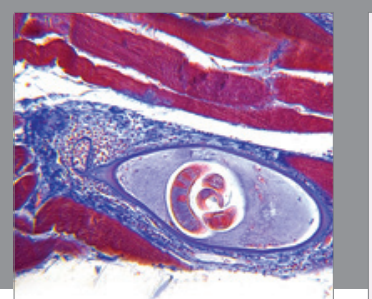

Gastroenterology Research and Practice

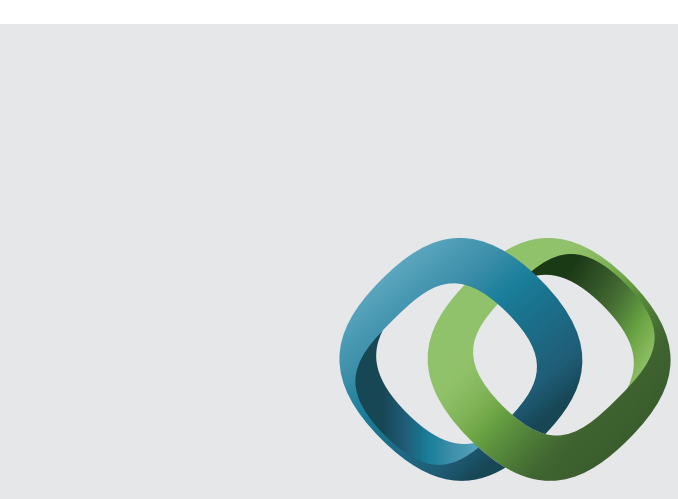

\section{Hindawi}

Submit your manuscripts at

http://www.hindawi.com
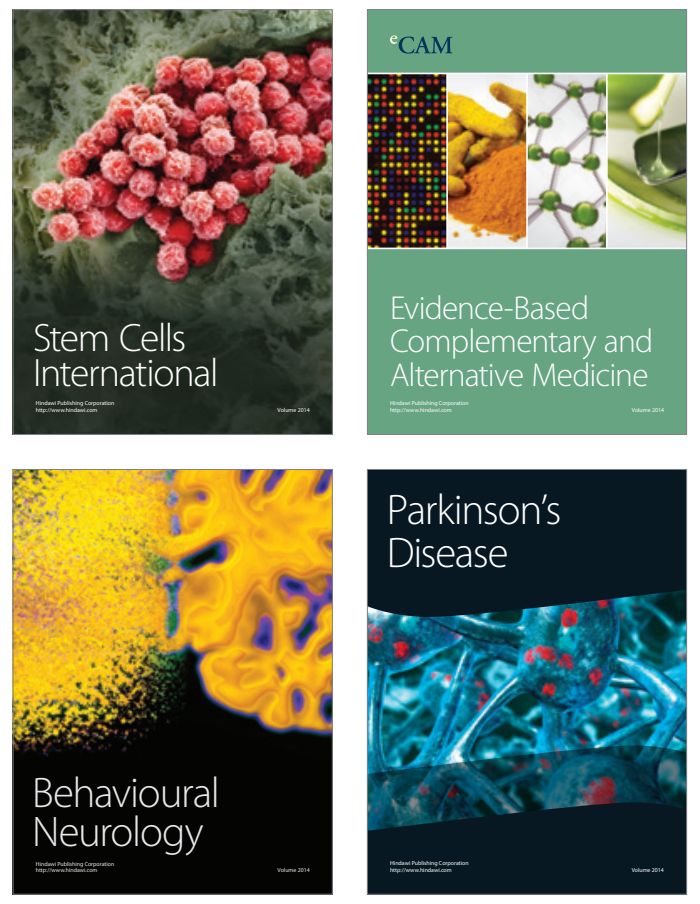
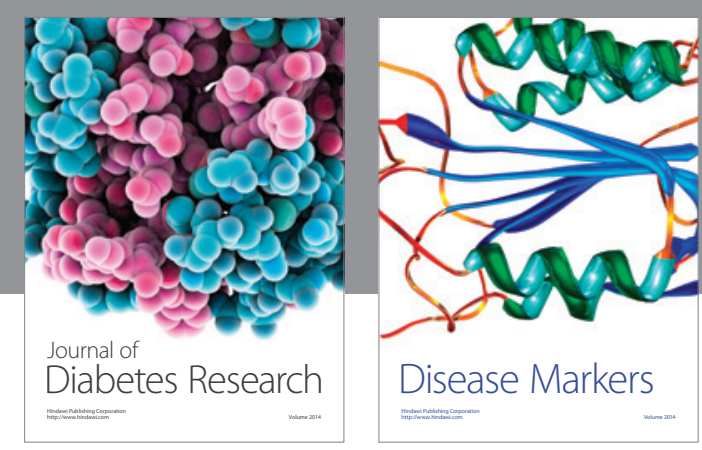

Disease Markers
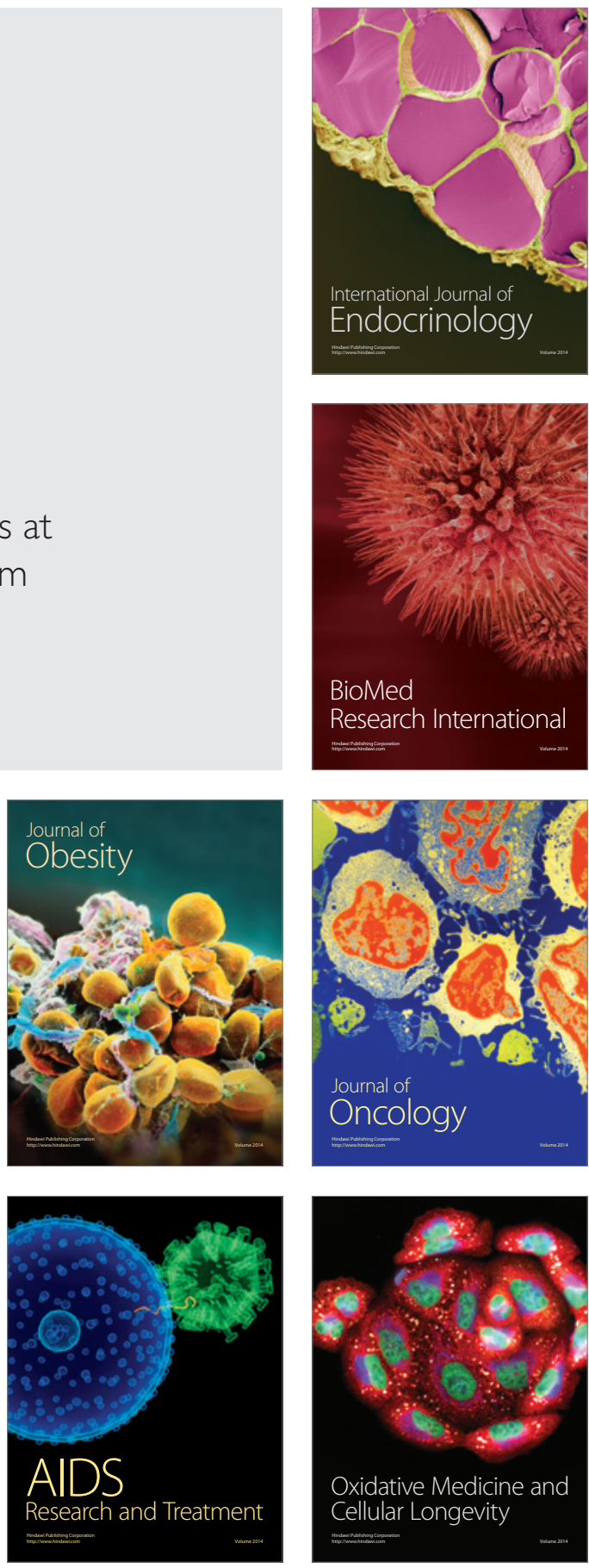